\title{
Reducing Students' Public Speaking Anxiety by Developing International Seminar School Project Task
}

\author{
D Apriyanti ${ }^{1}$ \\ Politeknik Negeri Padang, Kampus Limau Manis, Padang, Indonesia ${ }^{1}$ \\ Department of English, Politeknik Negeri Padang, Padang, Indonesia ${ }^{1}$ \\ \{difi_apriyanti@yahoo.com\}
}

\begin{abstract}
Public Speaking plays an important role in self-development since being a public speaker, the person must speak fluently in front of the audience, and at the same time she must control her anxiety and grab the audiences' attention. Since it is not an easy thing, these characteristics must be built. Therefore, teachers of this course must provide an appropriate task which sharpens these skills. In this research, a task named International Seminar School Project Task is designed. It is a task which sharpens nearly all characteristic of a public speaker. This task is given to two Public Speaking classes in English Department PNP, which consists of 50 students totally. To know the result of this task, questionnaires and assessments are carried out. There are 45 students who said that this task is so challenging but it gives satisfaction for them. They feel more confident now if they are asked to speak in front of many people. The opinion is equal with the result from public speaking rubric. It can be concluded that the students are in level high for their performance.
\end{abstract}

Keywords: School Project Task, International Seminar, Public Speaking Anxiety.

\section{Introduction}

International cooperation among companies takes place in this globalization era. A good understanding and interest are built to reach one agreement among them. Therefore, public speaking skills are needed. Being a public speaker does not only mean having good verbal but also having high confidence, passion, introspection, and awareness. "Speech anxiety is a very common form of social anxiety, and many individuals with speech anxiety have subclinical social anxiety". So, it is very clear that public speaking is a very challenging skill and must be acquired in advance.

Considering the need of acquiring public speaking skills, college students tend to take the course. They realize that they will face their fear during their performance [1]. The most common expressions of fears are shaky hands, dry mouth, sweaty hands, quivering voice, cold sweaty palms, and pounding heart. The fear usually exists at the beginning, during the first five minutes of standing, and the last five minutes of standing in front of the audiences [2].

Being a public speaker, they must be able to engage with their audiences and be aware of the audience's lost interest [3]. They also must pay attention to their voices such as tone, speed, accent, pitch, and clarity [4], as well on the body movement during performance [3]. Since the responsibility being a public speaker is high, teachers and researchers have done many studies 
to solve the fear of public speaking such as s video self-modeling [5], and training [6]. However, none have done a study on using university events -such as International Seminar-as a practice place for being a real public speaker.

English Department of State Polytechnic of Padang (PNP) has a goal to produce students who are professional in public speaking. Unfortunately, the tasks that were given by the teacher did not sharpen all the characteristics of a public speaker. Thus, students' performance is still low. The students need to feel the real anxiety of being a public speaker. They need to step out of their comfort classroom and friends. Therefore, a task which is named International Seminar School Project Task is designed.

International Seminar School Project is designed based on Task-Based Language Teaching (TBLT) approach. TBLT offers students material which they have to actively engage in the processing of in order to achieve a goal or complete a task. The chronology of task-based lessons consists of pre-task, during-task, and post-task. Pre-task means various activities that can be undertaken by teachers and students before the task is started. During-task means the task itself is centered and various instructional options, while post-task is procedures that follow up the task performance [7].

TBLT provides opportunities for students to explore and experiment their written and spoken the language through learning tasks that are designed to engage students in the authentic, practical and functional use of language for meaningful purposes. The role of TBLT is to stimulate a natural desire in students to improve their language competence by challenging them to complete meaningful tasks [8].

In designing a task based on TBLT, the teacher must consider that (1) The type of language that is being learned will involve the 'real world' situation and will prepare students to communicate in circumstances beyond the classroom; (2) this method is learner-centered, which promotes minimal teacher input during the task to allow students the freedom to use the target language, in addition to language already learn.; (3) tasks are based on meaning rather than form and language to encourage students to speak naturally with their peers, and (4) throughout the task, students are working a distinct outcome to signify successful completion of the task [9].

Since International Seminar Project Task takes and implements is based on TBLT, the concept of experiential learning is taken in the implementation. Experiential learning takes immediate personal experience as the point of departure for the learning experience. Students' intellectual growth when they engage in and reflect on sequences of tasks [8].

The rest of this article is organized as follows: Section 2 explains the method. Section 3 presents the model of the International Seminar School Project Task. Section 4 depicts the research and discussion. Section 5 concludes the paper.

\section{Method}

In this research, ADDIE model was used. ADDIE is an instructional system design model for building effective education and training in five phases: analysis, design, development, implementation, and evaluation [10]

These five phases also occurred during creating International Seminar School Project Task.The first phase- analyzing- was institution and organization that need a public speaker, students who are taking Public Speaking course in English Department of PNP, teachers of Public Speaking in English Department of PNP, and analyzing the document which is Public Speaking syllabus.

In analyzing phase, distributing questionnaires and conducting the interview was done to institution to find out criterion of a public speaker that they need. While for students, the purpose 
is to find out what they are expecting to get and what they are getting now from Public Speaking class. For the teachers, it is for knowing the ability of the students' public speaking skills and what tasks they have given to the students. The answer is then related to analyses of the syllabus. Overall, analysis is carried out to find out the currents situation and the need or expectation.

The result is the institution needs a public speaker who is able to perform in English, has high confidence, and smart. While the result from the students is less confident becomes the border for them to do improvisation to their voice and body movement. Meanwhile, the result of the teachers is quite similar to the students. The teacher sees that the students are not creative during their performance and all the presentations are carried out in the classroom and in front of their classmates.

From analyzing, it went to designing the desired performance and appropriate testing method. It can be seen that the students need more challenging tasks. They need to feel the feeling being a real public speaker. Therefore, International Seminar School Project Task was designed. It was designed based on characteristics of TBLT.

The third step was developing the International Seminar School Project Task. The task was shown to the institution and public speaking teachers whether International Seminar School Project can fulfill their needs and expectation. The fourth step was implementing. The learning environment was prepared and the students are engaged. The International Seminar School Project Task was implemented in Public Speaking classroom in English Department PNP. The last phase was evaluation. The evaluation was assessing the quality of the task and the process, both before and after implementation. International Seminar School Project Task was evaluated by using rubric of Public Speaking.

During the development of the International Seminar School Projects Task, several instruments were used such as questionnaires, interview lists, recorders, hand cam, and field notes.

\section{Model of International Seminar School Project Task}

The International Seminar School Project Task has steps to be followed and have guidance in the implementation. The steps must be acquired by the Public Speaking teacher and implemented it in sequence based on the list.

\section{I Preparation before International Seminar School Project Task}

Preparations before performing the International Seminar School Project Task are:

1. Grouping the students into small groups (beforehand, the teacher has decided the roles needed for the seminar).

2. Telling to the students that they have to decide the person for each role that is given by the teacher. Since it is a seminar, there will be a master of ceremony (MC), presenter, moderator, poet or storyteller, and reporter.

3. Ask each group to choose ahead of the committee. The person who is in charge of group activities.

4. Tell the preparation needed by each role, such as the MC prepares the que cards, the presenter prepares the speech which will be delivered, the moderator prepares the note, the poet or storyteller prepares the story or poet, the reporter prepares the note, and the cameraman prepares the camera and knowing all the events sequence. 


\subsection{The Sequence of International Seminar School Project Task}

Since the School Project is an international Seminar, the sequences are first, the MC holding the que card and start opening the event. The MC invites the head of the committee. Secondly, the head of committee delivers opening speech. Thirdly, the MC invites the first speaker. Fourthly, the first speaker delivers his/her speech. Fifthly, the moderator leads the discussion. Sixthly, poetry or story is presented as entertainment before the next speaker. Seventhly, the MC invites the second speaker. Moderator still leads the discussion. Eighthly, the MC closed the event, and the last, the reporter reports the seminar that has just finished. The cameramen record all the activities from beginning to end.

\subsection{The Rules of International Seminar School Project Task}

The rules of the task are 1.teacher must be selective in grouping in order each group consists of various types of students, 2 . The teacher must tell each group that the success of the group comes from the whole performance as one package, not from individual performance, 3 . All the performance is in English, including the poetry and story, 4. All the performance is carried out outside their class, in front of students from other departments, and 5. The time for the preparation is determined, and the progress is reported. (for example every week).

\section{Results and Discussion}

International Seminar School Project Task was implemented in the Public Speaking class. There were two classes $2 \mathrm{~A}$ and $2 \mathrm{~B}$. The total numbers of the students are 50 .

The students were conducting the task outside their classroom and their presentation or performance were listened by students from other Department which were from the Mechanical Department and Civil Department. The audience was around 25 students.

During doing the task, the students were graded. The assessment was focusing on the delivery. The delivery consists of five points which are (A) demonstrate awareness of listeners' needs, (B) speaks clearly with appropriate vocabulary and information, (C) uses tone, speed, and volume as tools, (E) demonstrate complexity of vocabulary and thought, and (E) appears comfortable with audience.

The result is: For point A, there were 45 students got five and 5 students got four. For point $\mathrm{B}$, there were 45 students got five and 5 students got four. For point $\mathrm{C}$, there were 47 students got five and 3 students got four. For point D, there were 40 students got five and 10 students got four. For point E, there were 45 students got five and 5 students got four.

It can be concluded that most students are at the level high. The task that the students did which was conducting an international seminar by having different roles with different responsible has encouraged the students' motivation and self-esteem. They feel challenged to give a perfect presentation in front of audiences that they do not know.

Meanwhile, from the questionnaire given to them after the task, most students answered that the task was a challenging task. They felt motivated and curious who would be their audience. They felt that they must give their best on their performance, and one of the reasons is to show their identity as English Department students. Most of them said that they tried to cover any mistake that they did during performance in order not be noticed by the audience. 


\section{Conclusions}

It is concluded that International Seminar School Project Task is a task that can be chosen for teaching Public Speaking. The task does not only sharpen the students' public speaking skill but also build their confidence. Their motivation is higher and they try to do their best because of their self-esteem and pride in being students from English Department.

\section{References}

[1] A. C. Ferreira Marinho, A. Mesquita de Medeiros, A. C. Côrtes Gama, and L. Caldas Teixeira, "Fear of Public Speaking: Perception of College Students and Correlates," J. Voice, vol. 31, no. 1, p. 127.e7-127.e11, Jan. 2017.

[2] R. R. Behnke and C. R. Sawyer, "Public speaking anxiety as a function of sensitization and habituation processes," Commun. Educ., vol. 53, no. 2, pp. 164-1173, Apr. 2004.

[3] D. O'Hair, R. Stewart, and H. Rubenstein, A speaker's guidebook: Text and reference. London: Macmillan, 2011.

[4] J. Lamerton, Public Speaking (Everything You Need To Know). New York: Harpercollins Publishers, 2001.

[5] A. Kruger, "The Use of Video Self-Modeling to Treat Public Speaking Anxiety," Minnesota State University, 2013.

[6] C. Spieler and R. Miltenberger, "Using awareness training to decrease nervous habits during public speaking,” J. Appl. Behav. Anal., vol. 50, no. 1, pp. 38-47, Jan. 2017.

[7] M. Hashemi, M. Azizinezhad, and S. Darvishi, "Using task- based language teaching, learning practically in English classes," Procedia - Soc. Behav. Sci., vol. 31, pp. 526$529,2012$.

[8] D. Nunan, "Task -based Language Teaching." 2004.

[9] P. SKEHAN, "A Framework for the Implementation of Task-based Instruction," Appl. Linguist., vol. 17, no. 1, pp. 38-62, Mar. 1996.

[10] R. K. Almomen, D. Kaufman, H. Alotaibi, N. A. Al-Rowais, M. Albeik, and S. M. Albattal, “Applying the ADDIE-Analysis, Design, Development, Implementation and Evaluation-Instructional Design Model to Continuing Professional Development for Primary Care Physicians in Saudi Arabia," Int. J. Clin. Med., vol. 7, no. 8, pp. 538-546, 2016. 